\title{
Zentralvorstandssitzung vom 21. September 2012
}

Spitalrechnungen - Der ZV spricht sich dafür aus, dass auf DRG-Rechnungen konsequent nur gruppierungsrelevante Angaben gemacht werden dürfen. Der von santésuisse und $\mathrm{H}+$ dem BAG eingereichte und von diesem im Verordnungsentwurf übernommene Vorschlag respektiert diese Grenze nicht und wird deshalb vom ZV abgelehnt. Mehr dazu erfahren Sie im Editorial der Schweizerischen Ärztezeitung 43.

Umsetzungspapiere zu HTA - SwissHTA erarbeitete zur Institutionalisierung und Methodik von HTA (Health Technology Assessment) in der Schweiz drei Umsetzungspapiere. Der Zentralvorstand (ZV) stimmt diesen trotz einiger Differenzen bei Detailfragen zu und spricht sich in der Frage zur HTA-Institution für die Variante einer öffentlich-rechtlichen Anstalt aus.

Befragung zur Hausarztmedizin - Von April bis Juni 2012 fand im Rahmen des Commonwealth Fund eine Befragung zur Hausarztmedizin in verschiede- nen Ländern statt, u.a. mit 1000 in der Schweiz tätigen Grundversorgern. Gemeinsam mit Hausärzte Schweiz konnte der ZV einige Fragen einbringen, welche speziell die Grundversorgung in der Schweiz berücksichtigen. Die Resultate der Befragung werden im November in Washington D.C. vorgestellt und danach auch in der Schweizerischen Ärztezeitung publiziert.

Beratung von Schwangeren - Im Rahmen des nationalen Programms «Alkohol/NPS» soll auf wissenschaftlicher Basis ein Konsens für die Beratung Schwangerer in Bezug auf Risiken bei Alkoholkonsum gefunden werden. Die FMH engagiert sich seit den 90er Jahren in den nationalen Präventionsprogrammen und arbeitet eng mit Sucht Schweiz zusammen. Nun gilt es, die Broschüre zum Thema «Schwangerschaft und Alkohol» zu aktualisieren, damit die Botschaften an den Hausarzt, die Gynäkologin und an die Suchtfachstellen immer dieselben sind.

\section{Bringt Vorteile. Die Mitgliedschaft in der FMH.}

Wir machen uns stark für Sie. Mit engagierter Standespolitik und attraktiven Services: TarifInfoline, Rechtsauskünfte, Musterverträge.

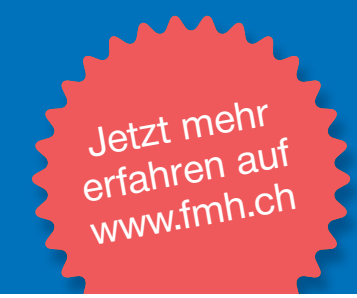

